Article

\title{
Poly(Oxyethylene)-Amidoamine Based Gemini Cationic Surfactants for Oilfield Applications: Effect of Hydrophilicity of Spacer Group
}

\author{
S. M. Shakil Hussain, Ahmad Mahboob and Muhammad Shahzad Kamal *D \\ Center for integrative Petroleum Research, King Fahd University of Petroleum \& Minerals, \\ Dhahran 31261, Saudi Arabia; smshakil@kfupm.edu.sa (S.M.S.H.); ahmad.mahboob@kfupm.edu.sa (A.M.) \\ * Correspondence: shahzadmalik@kfupm.edu.sa; Tel.: +966-13-8608513; Fax: +966-13-60-3989
}

Received: 9 February 2020; Accepted: 21 February 2020; Published: 26 February 2020

check for updates

\begin{abstract}
Thermal stability, salt tolerance, and solubility in normal and high salinity brine are the major requirements for any surfactant designed for oilfield applications because the surfactant stays in a non-ambient environment inside the reservoir for a long period of time. Herein, a series of new gemini cationic surfactants (GSs) with varying spacer hydrophilicity were synthesized and elucidated using MALDI-ToF-MS, NMR $(1 \mathrm{H}, 13 \mathrm{C})$, as well as FTIR spectroscopy. GSs found to be soluble in normal as well as high salinity brine and aqueous stability tests revealed that GSs possess the ability to retain their structural integrity at high salinity and high temperature conditions because no suspension formation or precipitation was detected in the oven aged sample of GSs at $90{ }^{\circ} \mathrm{C}$ for 30 days. Thermal gravimetric analysis displayed a higher decomposition temperature than the real reservoir temperature and the GS with a secondary amine spacer exhibited high heat stability. The significant reduction in surface tension and critical micelle concentration was observed using $1 \mathrm{M} \mathrm{NaCl}$ solution in place of deionized water. The difference in surface tension and critical micelle concentration was insignificant when the $1 \mathrm{M} \mathrm{NaCl}$ solution was replaced with seawater. The synthesized surfactants can be utilized for oilfield applications in a challenging high temperature high salinity environment.
\end{abstract}

Keywords: poly(oxyethylene); synthesis; thermal; surface; oilfield

\section{Introduction}

Surfactants are extensively applied in the petroleum industry such as enhanced oil recovery (EOR) [1-5], fracking fluid [6], swelling prevention [7], reservoir stimulation [8], corrosion inhibitor [9], drag reduction [10], and drilling mud [11,12]. Surfactants minimize the interfacial tension (IFT) of crude oil and aqueous phase as well as alter the wettability of oilfield rocks [13-15]. There are different classes of surfactants such as cationic, anionic, and zwitterionic as well as nonionic, and the choice of an appropriate class exclusively relies on the type of oilfield. As an example, negatively charged surfactants are avoided in carbonate reservoirs and positively charged surfactants are avoided in sandstone reservoirs because of their high adsorption.

Gemini surfactants (GSs) belong to a novel class that contains more than one conventional surfactant joined by the spacer group. GSs display unique chemical, physical, and aggregation morphologies compared to those of single head single tail surfactants. The important features of GSs are smaller critical micelle concentration (CMC), good solubilizing capability, antibacterial activity, required low quantity, and unique aggregation behavior [16]. Due to these distinctive properties, GSs have found application in the oilfield industry.

The nature of the spacer group is perhaps the most indispensable factor that controls the chemical and physical properties of the GSs because the spacer can handle hydrophobic interaction and 
constrain the repulsion of the hydrophilic headgroup. The spacer group can be short [17-19], long [20], hydrophilic [21], hydrophobic [22], rigid [23], flexible [24], aromatic [25], etc. Zhou et al. studied the swelling inhibition properties of GSs with different lengths of the lipophilic tail and hydrophilic spacer group and observed that the spacer could increase the interaction with montmorillonite clay by hydrogen bonding, but an overlong spacer could lead to poor inhibition performance [26]. Mao et al. reported the synthesis of a gemini cationic surfactant with a methylamine and epoxy chloropropane spacer for thickening material and applied in fracturing fluid applications [27]. They claimed the synthesized material exhibited good temperature stability and in the following report, they developed an efficient method for recycling the same surfactant gel from the flowback fluid [28]. Pal and co-workers investigated the influence of the length of the spacer in a gemini cationic surfactant for EOR. They observed an increase in oil recovery efficiency by increasing the length of the spacer in the order of $29.83 \%, 31.73 \%, 33.83 \%$, and $34.55 \%$ by using $3,4,5$, and 6 carbons in the spacer group, respectively [19]. Migahed et al. reported the synthesis of two gemini cationic surfactants containing different spacer lengths as anti-corrosion for X-65 steel dissolution in oilfields produced water under sweet conditions [29]. They observed that the surfactant with a shorter spacer length exhibited better inhibitive properties than the surfactant with a comparatively larger spacer length. Similarly, Cao et al. observed lower CMC values of the synthesized gemini surfactant containing four ethoxy units in the spacer group compared with the corresponding gemini surfactant with eight ethoxy units in the spacer group [30].

Aqueous stability or solubility of the surfactant is an essential parameter for a required formulation, which expressively affects the propagation of the surfactant inside the reservoir. Commercial surfactants suffer due to low aqueous stability or solubility in high salinity reservoir brine ( $\approx 22,000 \mathrm{ppm})$. For example, alkylbenzene sulfonates show cloudiness when they encounter alkali and avoid the requirement of the transparent solution in the surfactant formulation stage [31]. Surfactants used in oilfield applications must be chemically stable in high temperatures and high salinity environments for several days to months because these harsh conditions significantly affect the chemical stability of the surfactant inside the reservoir.

The objectives of this work include (1) synthesis of three new gemini cationic surfactants (GSs) containing a diethyl ether spacer (g1), secondary amine spacer (g2), isopropyl alcohol spacer (g3), and the spectral characterization with the aid of MALDI-ToF-MS, FTIR, 1H, and 13C NMR; (2) aqueous stability tests of the GSs for 30 days at $90{ }^{\circ} \mathrm{C}$ in seawater (SW), formation water (FW), and distilled water (DW); (3) the heat resistance experiment of GSs using thermal gravimetric analysis (TGA); and (4) the influence of different hydrophilic spacer groups onto the aggregation behavior. The chemical structures were sensibly planned in order to acquire certain properties. For example, the GSs with a hydrophilic spacer showed a lower CMC in comparison with the corresponding GSs containing a hydrophobic spacer group [32]. The solubility of the GSs in normal and high saline water was achieved by adding a sufficient number of ethoxy units [33].

\section{Materials and Synthesis}

\subsection{Materials}

Bis(2-chloroethyl)amine hydrochloride (98\%), 3-(dimethylamino)-1-propylamine (99\%), bis(2-bromoethyl) ether (95\%), glycolic acid ethoxylate lauryl ether (average $\left.\mathrm{M}_{\mathrm{n}} \sim 690\right), \mathrm{NaF}(\geq 99 \%)$, 1,3-dichloro-2-propanol (98\%), and $\mathrm{Al}_{2} \mathrm{O}_{3}$ (99.99\%) were received from Aldrich. The SW and $\mathrm{FW}$ were formed through the addition of a specific amount of $\mathrm{MgCl}_{2}, \mathrm{CaCl}_{2}, \mathrm{NaHCO}_{3}, \mathrm{Na}_{2} \mathrm{SO}_{4}$, and $\mathrm{NaCl}$ (Table 5), and the material was received from Panreac.

\subsection{Structure Determination}

The NMR study was done using the Bruker machine (500 MHz, Jeol, Tokyo, Japan) by using tetramethylsilane (TMS) as an internal standard. The NMR (proton and carbon-13) was conducted in 
the deuterated solvent and the graph was plotted in ppm. The FTIR study was performed on the 16F model of the Perkin-Elmer instrument (Waltham, MA, USA) and the FTIR graph was plotted in $\mathrm{cm}^{-1}$. The MALDI-ToF-MS analysis was performed using a Bruker SolariX XR instrument (Bruker, Billerica, MA, USA).

\subsection{Solubility Tests}

Five wt \% of $\mathbf{g 1}$, g2, and $\mathbf{g} \mathbf{3}$ was solubilized in SW, FW, and DW, followed by oven aging for 30 days at $90^{\circ} \mathrm{C}$ and the solubility was visually detected. Stability was confirmed by NMR.

\subsection{Thermal Gravimetric Analysis (TGA)}

A SDT Q600 machine (TA instrument, New Castle, DE, USA) was employed for TGA measurements. Tests were done in a continuous heating rate $\left(20^{\circ} \mathrm{C} / \mathrm{min}\right)$ and a stable flow of nitrogen $(100 \mathrm{~mL} / \mathrm{min})$ with a $30{ }^{\circ} \mathrm{C}$ to $500{ }^{\circ} \mathrm{C}$ temperature interval.

\subsection{Surface Tension Experiments}

Surface tension experiments of $\mathbf{g 1}, \mathbf{g} 2$, and $\mathbf{g} \mathbf{3}$ were done using a force tensiometer (Sigma 702, Biolin Scientific, Gothenburg, Sweden) using the Wilhelmy plate method. Measurements were performed at $25 \pm 0.1^{\circ} \mathrm{C}$ with proper cleaning of the plate. The surface tension value of DW was used as a standard. The surface tension at each concentration was repeated five times. The surface tension standard deviation ranged from $\pm 0.0390 \mathrm{mN} / \mathrm{m}$ to \pm 0.0999 for different readings.

\subsection{Synthesis}

\section{Synthesis of $\mathbf{g} \mathbf{1}$}

g1 was synthesized by the amidation of glycolic acid ethoxylate lauryl ether (6) (100 g, $144.93 \mathrm{mmol})$ with 3-(dimethylamino)-1-propylamine 5 (29.62 g, $289.85 \mathrm{mmol})$ using $\mathrm{NaF}(0.61 \mathrm{~g}, 14.49 \mathrm{mmol})$ in a $500 \mathrm{~mL}$ flask up to $8 \mathrm{~h}$ at $160^{\circ} \mathrm{C}$ in an argon atmosphere (Scheme 1). The resulting water of the reaction was absorbed using $\mathrm{Al}_{2} \mathrm{O}_{3}$. After $8 \mathrm{~h}$, additional compound $5(22.21 \mathrm{~g}$, $217.39 \mathrm{mmol})$ was injected with continued stirring for an extra $6 \mathrm{~h}$. After that, the leftover compound 5 was vaporized through reduced pressure and the solid $\mathrm{NaF}$ was filtered. The resulting product was dried to obtain compound 4 [34]. In the following step, compound $4(25.0 \mathrm{~g}, 32.30 \mathrm{mmol})$ was treated with bis(2-bromoethyl) ether $(3.26 \mathrm{~g}, 14.04 \mathrm{mmol})$ using dried $\mathrm{EtOH}(5 \mathrm{~mL})$ for $48 \mathrm{~h}$ at $80^{\circ} \mathrm{C}$. Eventually, the solvent was extracted and the column chromatography was conducted by an ethanol-based mobile phase to acquire $\mathbf{g} \mathbf{1}$ in a gel-like material [35].

The $\mathbf{g} 2$ and $\mathbf{g} 3$ were also synthesized using the same procedure respectively.

\section{Results and Discussion}

Scheme 1 shows the synthesis of gemini surfactants (g1, g2, and g3). 3-(dimethylamino)1-propylamine (5) was stirred with glycolic acid ethoxylate lauryl ether (6) using $\mathrm{NaF}$ at $160{ }^{\circ} \mathrm{C}$. Resulting compound 4 was separately reacted with bis(2-bromoethyl) ether, bis(2-chloroethyl)amine hydrochloride, and 1,3-dibromo-2-propanol to achieve the related g1, g2, and g3, respectively. Monomer formation is the expected side product of the reaction.

\subsection{Interpretation of the GS Structure}

The g1, g2, and g3 structures were identified using MALDI-ToF-MS, NMR, and FTIR. We emphasized the structure identification of $\mathbf{g} \mathbf{1}$ here as an example. Rendering the $1 \mathrm{H}$ NMR data of $\mathbf{g} 1$ (Table 1, Figure 1), the peaks at $\delta 0.88 \mathrm{ppm}$ and $\delta 1.26 \mathrm{ppm}$ could be referred to the $\mathrm{CH}_{3}$ and $\mathrm{CH}_{2}$ groups in the lipophilic tail, respectively. The signal at $\delta 3.39 \mathrm{ppm}$ could be assigned to two methyl groups of the positively charged ammonium head $\left[\mathrm{N}^{+}\left(\mathrm{CH}_{3}\right)_{2}\right]$. Multiple signals of ethoxy were 
detected as an overlapped peak at $\delta 3.61-3.70 \mathrm{ppm}$. The broad peak at $\delta 7.79 \mathrm{ppm}$ could be allocated to an amide group $[\mathrm{NH}(\mathrm{CO})]$.

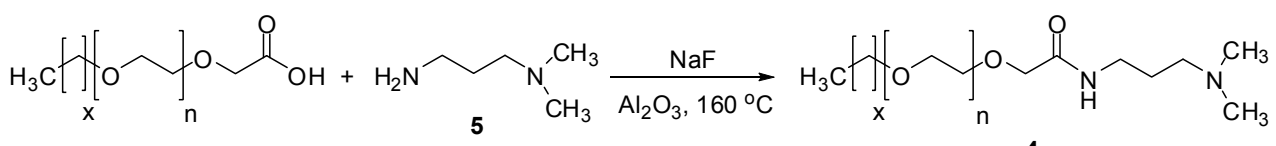
$\mathrm{x}=11-13$ Average $\mathrm{Mn} \sim 690(\mathbf{6})$

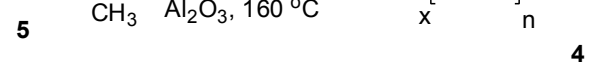

$$
\begin{aligned}
& \underset{\mathrm{EtOAC}, 80^{\circ} \mathrm{C}}{\mathrm{C}} \overbrace{\mathrm{S}} \\
& \mathrm{X}=\mathrm{Br} ; \mathrm{s}=-\mathrm{H}_{2} \mathrm{C}-\mathrm{O}-\mathrm{CH}_{2}-\quad \text { (g1) } \\
& \mathrm{X}=\mathrm{Cl} ; \mathrm{s}=-\mathrm{H}_{2} \mathrm{C}-\stackrel{\mathrm{H}}{\mathrm{N}}-\mathrm{CH}_{2}-\text { (g2) }
\end{aligned}
$$

\begin{tabular}{|c|c|c|c|c|c|c|c|c|c|c|}
\hline \multirow{3}{*}{ GSs } & \multicolumn{10}{|c|}{ Proton NMR ( $\delta$ in ppm, $500 \mathrm{MHz}, \mathrm{CDCl}_{3}$ ) } \\
\hline & \multicolumn{3}{|c|}{ Lipophilic Tail } & \multirow{2}{*}{$\begin{array}{c}\begin{array}{c}\text { Ethoxy \& } \\
\text { Spacer }\end{array} \\
\mathrm{CH}_{2}(\mathrm{~d}, \mathrm{i})\end{array}$} & \multirow{2}{*}{$\begin{array}{c}\text { Acetic } \\
\mathrm{CH}_{2} \\
\text { (e) }\end{array}$} & \multirow{2}{*}{$\begin{array}{l}\text { Amide } \\
\text { Group } \\
\text { NH (f) }\end{array}$} & \multicolumn{2}{|c|}{$\begin{array}{l}\text { Amido-Amine } \\
\text { Group }\end{array}$} & \multicolumn{2}{|c|}{ Spacer } \\
\hline & $\begin{array}{l}\mathrm{CH}_{3} \\
\text { (a) }\end{array}$ & $\begin{array}{c}\mathrm{CH}_{2} \\
\text { (b) }\end{array}$ & $\begin{array}{c}\mathrm{CH}_{2} \\
\text { (c) }\end{array}$ & & & & $\begin{array}{l}\mathrm{CH}_{3}(\mathrm{j}) \\
\mathrm{CH}_{2}(\mathrm{~g})\end{array}$ & $\begin{array}{c}\mathrm{CH}_{2} \\
\text { (h) }\end{array}$ & $\begin{array}{c}\mathrm{CH}_{2} \\
(\mathbf{k})\end{array}$ & - \\
\hline g1 & 0.88 & 1.26 & 1.56 & 3.64 & 4.04 & 7.79 & 3.39 & 2.10 & 4.05 & - \\
\hline g2 & 0.88 & 1.26 & 1.57 & 3.68 & 4.00 & 7.82 & 3.44 & 2.11 & 3.44 & $\begin{array}{c}2.91 \\
(\mathrm{NH})\end{array}$ \\
\hline g3 & 0.87 & 1.26 & 1.56 & 3.65 & 4.00 & 7.93 & 3.41 & 2.07 & $\begin{array}{c}4.04 \\
(\mathrm{CH})\end{array}$ & $\begin{array}{l}3.65 \\
(\mathrm{OH})\end{array}$ \\
\hline
\end{tabular}

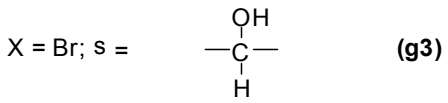

Scheme 1. Synthesis of gemini surfactants having various hydrophilic spacer group.

Table 1. $1 \mathrm{H}$ NMR readings describing the type of proton in $\mathbf{g 1 - g 3}[1,28,36,37]$.

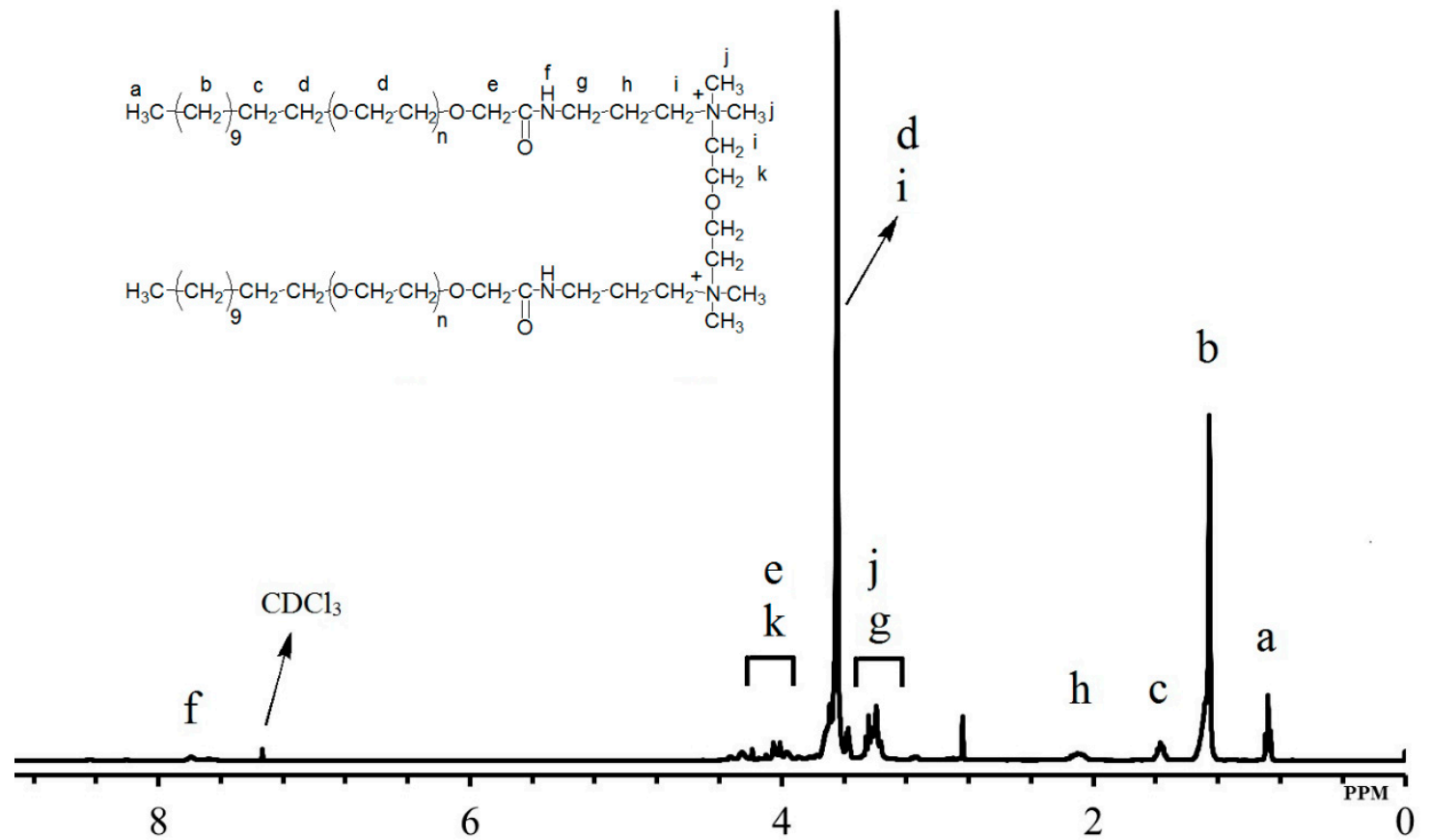

Figure 1. 1H NMR spectra and peak assignment of g1. 
Rendering the 13C NMR graph of g1 (Table 2, Figure 2), the signals at $\delta 13.9,25.9,31.7$, and 29.1-29.4 ppm could be assigned to the hydrocarbon of the lipophilic tail. The peak at $\delta 51.7 \mathrm{ppm}$ could be coupled with the two $\mathrm{CH}_{3}$ groups of the positively charged ammonium head $\left[-\mathrm{N}^{+}\left(\mathrm{CH}_{3}\right)_{2}\right]$. The signals detected at $\delta 62.9,63.3$, and $64.4 \mathrm{ppm}$ could be related to two methylene units of the spacer and one methylene unit next to ammonium head $\left[-\mathrm{O}-\mathrm{CH}_{2}-\mathrm{CH}_{2}-\mathrm{N}^{+}-\mathrm{CH}_{2}-\left(\mathrm{CH}_{3}\right)_{2}\right]$, respectively. The multiple peaks of methylene units $\left[-\mathrm{O}-\mathrm{CH}_{2}-\mathrm{CH}_{2}-\right]$ were observed at $\delta 69.0-71.5 \mathrm{ppm}$. The signal detected at $\delta 170.7$ ppm could be linked with the carbonyl carbon of amide $\left[\mathrm{CH}_{2} \mathrm{CONH}\right]$.

Table 2. 13C NMR readings in $\mathbf{g} 1-\mathrm{g} 3$.

\begin{tabular}{cc}
\hline GSs & 13C NMR (ppm, $\left.\mathbf{C D C l}_{3}, \mathbf{1 2 5} \mathbf{M H z}\right)$ \\
\hline g1 & $13.9,22.5,25.9,29.1,29.3,29.4,31.7,35.6,51.7,62.9,63.3,64.4,70.3,170.7$ \\
g2 & $14.1,22.6,26.0,29.1,29.3,29.4,31.9,35.7,51.7,60.8,61.5,70.2,170.9$ \\
g3 & $13.9,22.5,25.9,29.1,29.3,29.4,31.7,35.8,52.1,60.6,61.4,70.3,170.7$ \\
\hline
\end{tabular}

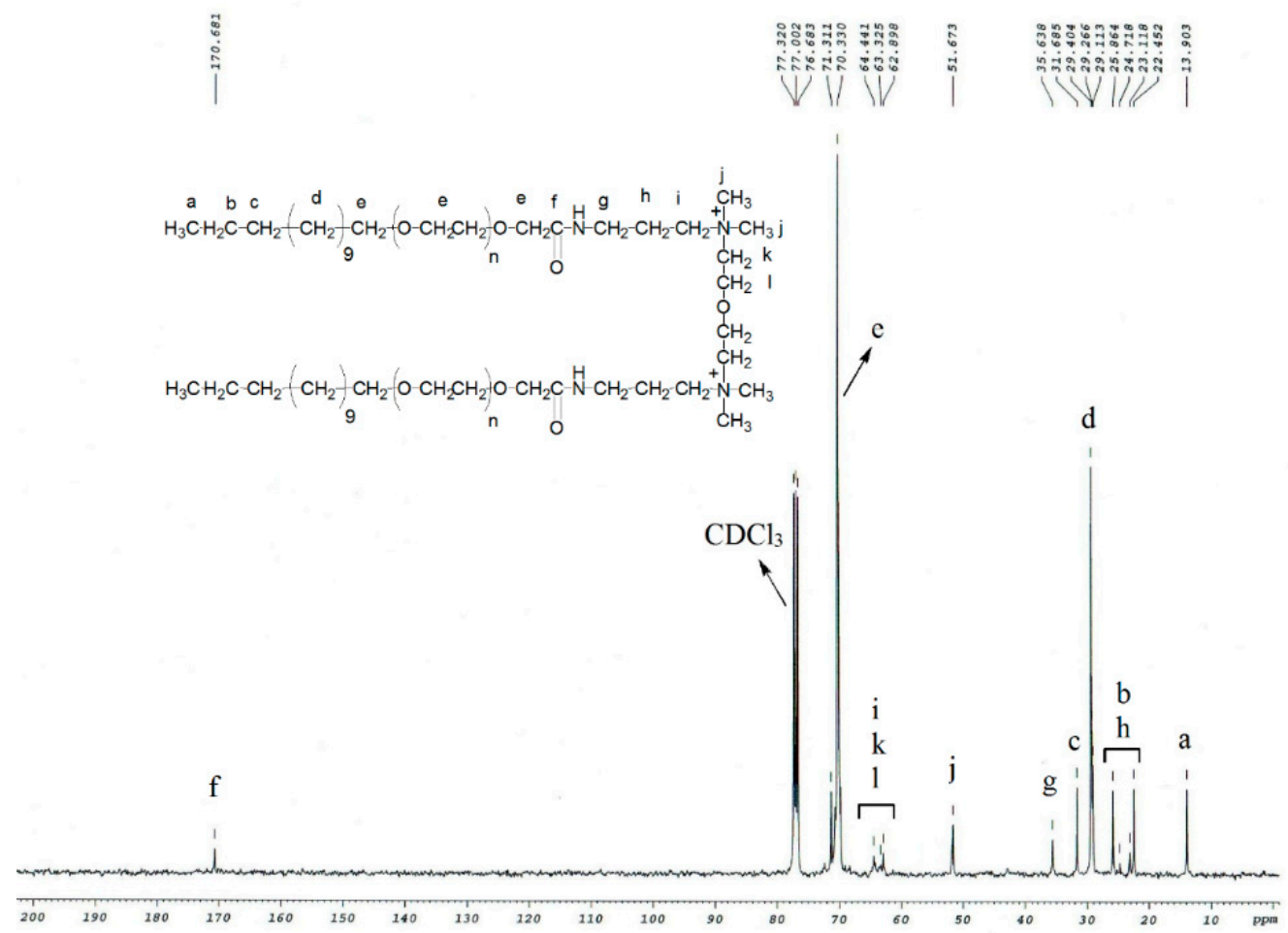

Figure 2. 13C NMR spectra and peak assignment of g1.

Rendering the FTIR spectra of g1 (Table 3, Figure 3), a broad adsorption peak at 3424/cm corresponded to the NH stretch. Two adsorption bands at 2922/cm and 2855/cm could be assigned to the $\mathrm{CH}_{2}$ asymmetric and symmetric motion, respectively. Two adsorption bands at 1656/cm, and 1544/cm could be linked to the amide (I) and amide (II) stretching, respectively [38]. The ethoxy units were identified by the adsorption signals at $1100 \mathrm{~cm}^{-1}$.

Table 3. FTIR readings showing adsorption values in g1-g3.

\begin{tabular}{cccccccccc}
\hline & \multicolumn{7}{c}{ FTIR Characteristic Values $\left.\mathbf{( c m}^{-\mathbf{1}}\right)$} \\
\cline { 2 - 10 } GSs & $\mathbf{N}-\mathbf{H}$ & $\begin{array}{c}\mathbf{C H}_{\mathbf{2}} \\
\text { asym. }\end{array}$ & $\begin{array}{c}\mathbf{C H}_{\mathbf{2}} \\
\text { sym. }\end{array}$ & $\begin{array}{c}\text { Amide } \\
\text { (I) }\end{array}$ & Amide (II) & $\begin{array}{c}\mathbf{C H}_{\mathbf{2}} \\
\text { (Bending) }\end{array}$ & $\begin{array}{c}\mathbf{C H}_{\mathbf{3}} \\
\text { (Bending) }\end{array}$ & $\begin{array}{c}\text { Ethoxy } \\
\text { Stretch }\end{array}$ & asym. \\
\hline g1 & 3424 & 2922 & 2855 & 1656 & 1544 & 1465 & 1349 & 1100 & 947 \\
g2 & 3397 & 2922 & 2855 & 1655 & 1546 & 1466 & 1349 & 1099 & 947 \\
g3 & 3412 & 2922 & 2855 & 1656 & 1544 & 1465 & 1349 & 1098 & 947 \\
\hline
\end{tabular}




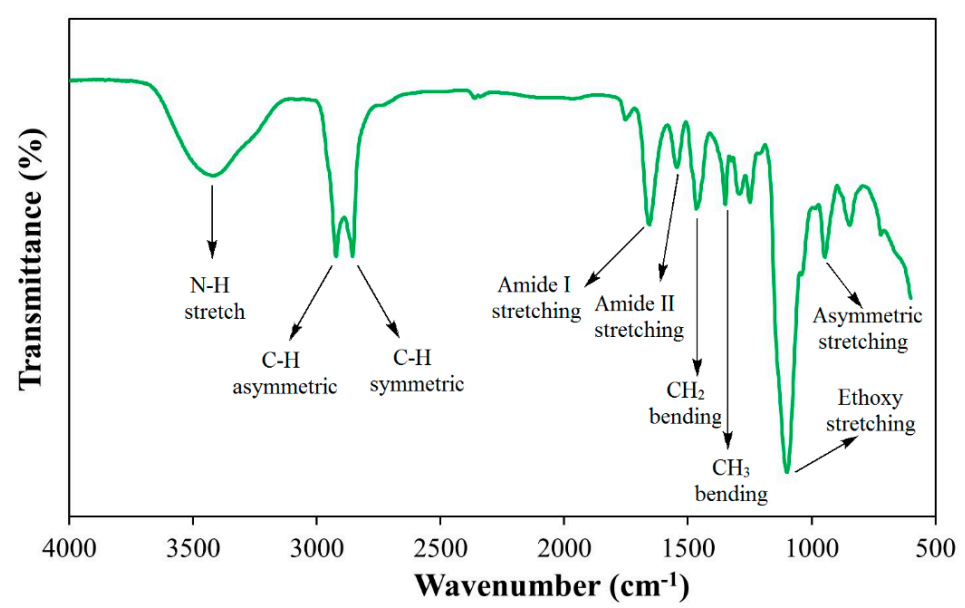

Figure 3. Infrared spectra and peak assignment of g1.

Usually, FTIR and NMR data are adequate to determine the chemical structure; however, for surfactants such as g1-g3, which contain high molecular weight along with a distribution of ethoxy groups, an additional technique such as MALDI-ToF-MS is important to acquire insights into the chemical structure of a gemini surfactant. Rendering the MALDI-ToF-MS of g1 (Table 4, Figure 4), the base peak was detected at $m / z$ 813.63. This may be attributed to the heterolytic bond breaking between the terminal carbon of the spacer and the quaternary- $\mathrm{N}$ promoted by the ether oxygen of the spacer group, which leads to the conclusion that $\mathbf{g} 1$ with $\mathrm{x}=11$ and $n=11$ is the chief component (Figure 4). The following peaks after and before the base peak in the MALDI-ToF-MS spectra indicate the distribution of ethoxy groups because the mass difference of these peaks was $m / z 44$, which is a mass of one ethoxy group. For example, the peak of $m / z 769.60$ was assigned to a molecular mass of g1 containing 10 ethoxy units $(\mathrm{x}=10, n=11)$ and the peak of $m / z 725.57$ referred to a molecular mass of $\mathbf{g} 1$ having nine ethoxy units $(x=9, n=11)$. Similarly, the signals of $m / z 681.54$ were assigned to a molecular mass of $\mathbf{g} 1$ containing eight ethoxy units $(x=8, n=11)$ and the peak of $m / z 637.51$ referred to a molecular mass of $\mathbf{g} 1$ with seven ethoxy units $(x=7, n=11)$. On the other hand, the peak of $m / z$ 857.65 was assigned to a molecular mass of $\mathbf{g} 1$ containing 12 ethoxy units $(x=12, n=11)$ and the peak of $m / z 901.68$ referred to a molecular mass of $\mathbf{g} 1$ with 13 ethoxy units $(x=13, n=11)$. Likewise, the signals of $m / z 945.71$ was assigned to a molecular mass of $\mathbf{g} 1$ containing 14 ethoxy units $(\mathrm{x}=14, n=11)$ and the peak of $m / z 989.74$ referred to a molecular mass of $\mathbf{g} 1$ with 15 ethoxy units ( $\mathrm{x}=15, n=11)$.

Table 4. MALDI-ToF-MS data of g1-g3.

GSs Base Peak




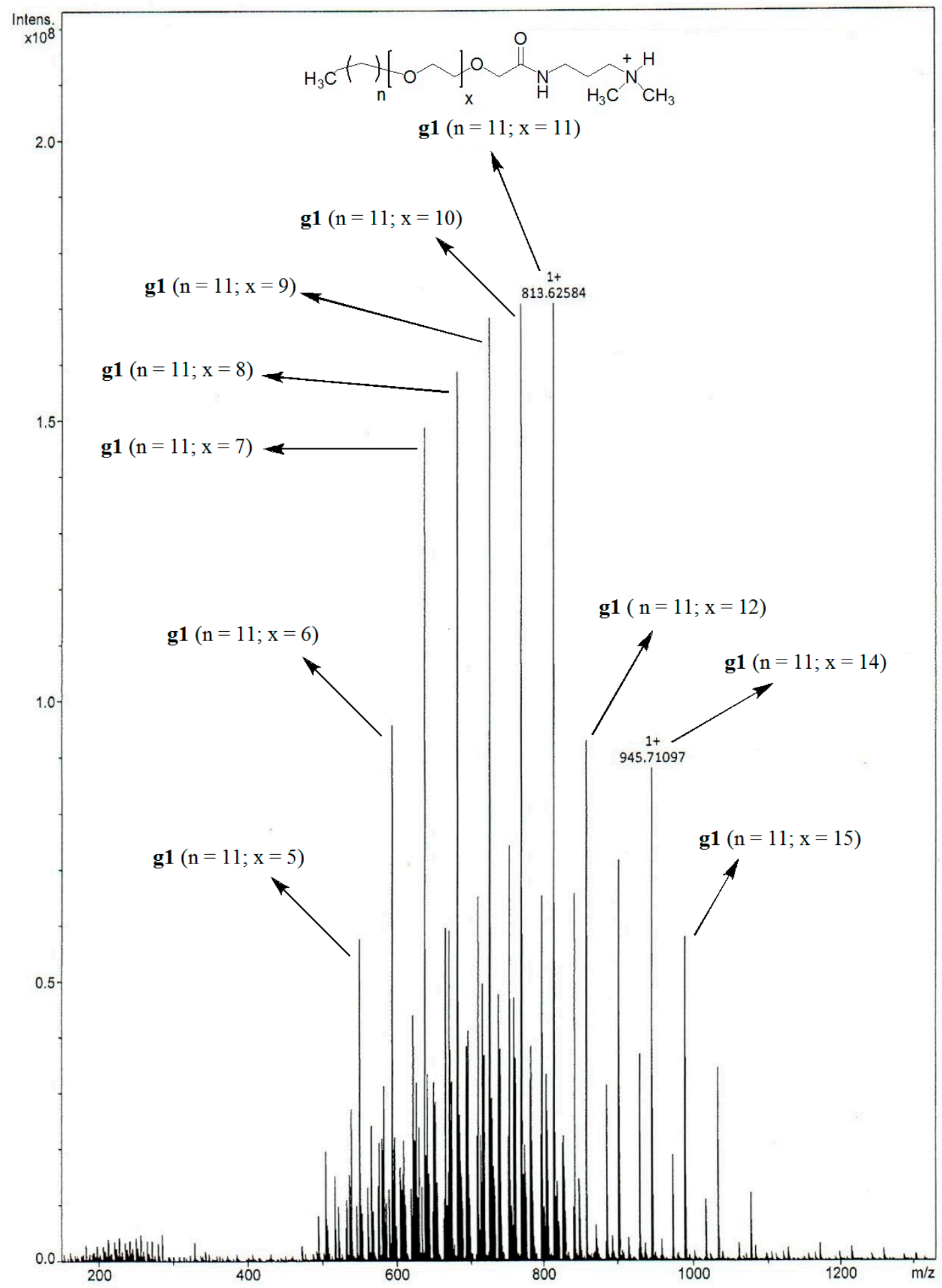

Figure 4. MALDI-ToF-MS spectra and peak assignment of g1.

In general, the MALDI-ToF-MS, FTIR, and NMR results are in agreement with the chemical structure of $\mathbf{g} 1$.

\subsection{Aqueous Stability and Solubility}

Surfactant tolerance in the presence of formation ions as well as solubility at high saline condition are the basic requirements for any new surfactant designed for oilfield applications. The synthesized 
g1, g2, and g3 displayed excellent solubility in deionized and saltwater because of the polyethoxylates present in the chemical structure (Figure 5) [33]. The aqueous stability and heat resistance experiments were done by solubilizing $\mathbf{g 1}, \mathbf{g} 2$, and $\mathbf{g} 3$ in SW, FW, and DW, followed by oven aging for 30 days at $90^{\circ} \mathrm{C}$. The salt concentration in the laboratory prepared FW and SW is shown in Table 5. Usually, solubility increases with an increase in temperature; however, temperature showed a negative impact on aqueous stability. The synthesized gemini surfactants (g1, g2, and g3) exhibited excellent solubility in normal as well as high saltwater and the transparent solution of the oven aged samples at $90^{\circ} \mathrm{C}$ for 30 days revealed that the $\mathbf{g 1}, \mathbf{g} \mathbf{2}$, and $\mathbf{g} \mathbf{3}$ are stable in normal and high saltwater because less stable and less soluble gemini surfactants tend to show precipitation or suspension formation under these harsh conditions. We further investigated the effect of heat on the chemical structure of the surfactants by doing 1H NMR analysis of the oven aged samples. As depicted in Figure S1 (Supplementary Materials), the $1 \mathrm{H}$ NMR spectra of the before aging and after aging samples of $\mathbf{g} 1$ matched, which further confirmed the stability of the surfactant under harsh conditions.

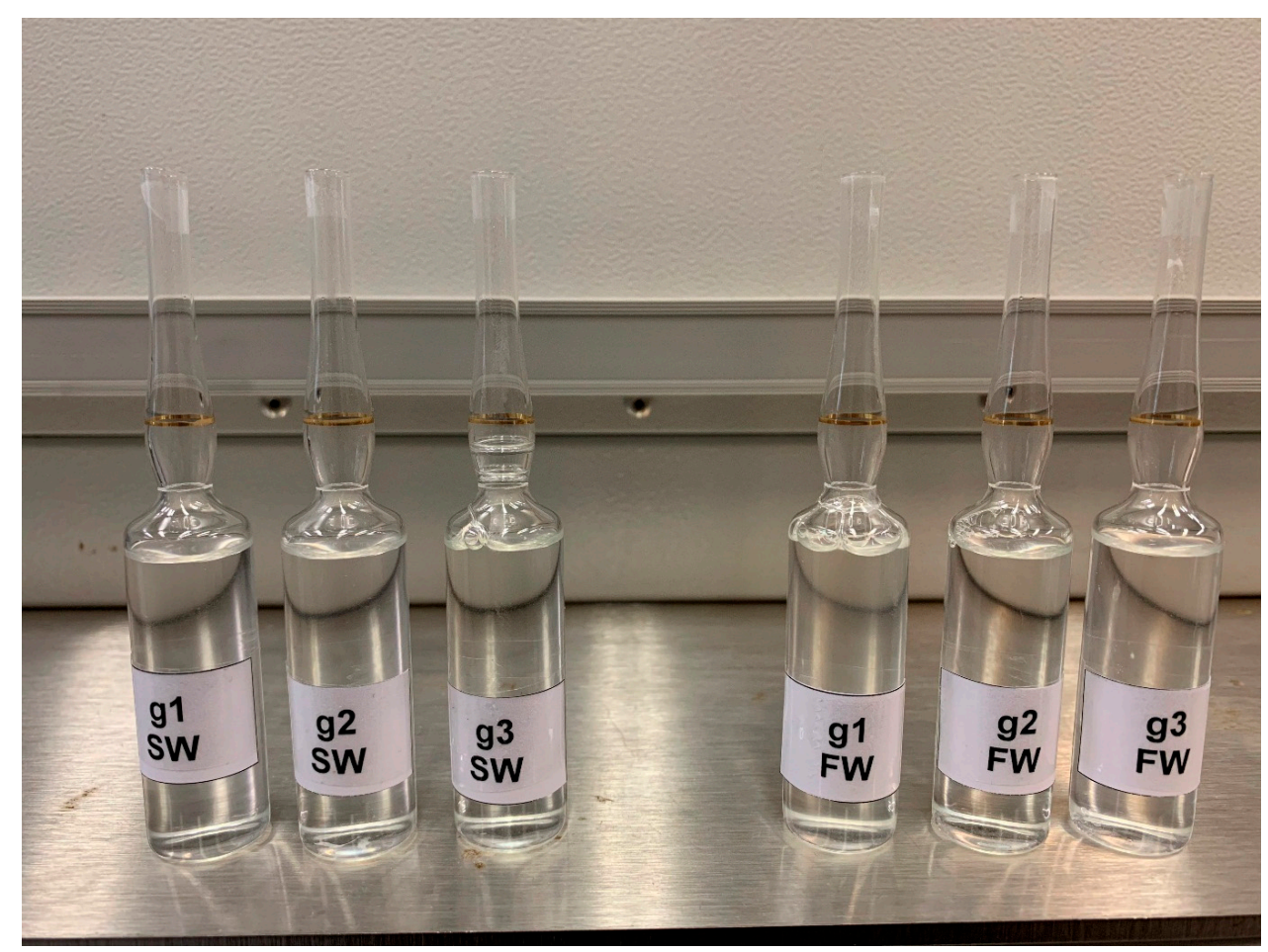

Figure 5. Snapshot of g1, g2, and g3 solutions in SW and FW.

Table 5. The specific concentration of salt in SW and FW.

\begin{tabular}{ccc}
\hline Ions & FW $(\mathrm{g} / \mathrm{L})$ & SW $(\mathrm{g} / \mathrm{L})$ \\
\hline $\mathrm{Na}^{+}$ & 59.5 & 18.3 \\
$\mathrm{Ca}^{2+}$ & 19.1 & 0.7 \\
$\mathrm{Mg}^{2+}$ & 2.5 & 2.1 \\
$\mathrm{SO}_{4}^{2-}$ & 0.4 & 4.3 \\
$\mathrm{Cl}^{-}$ & 132.1 & 32.2 \\
$\mathrm{HCO}_{3}{ }^{-}$ & 0.4 & 0.1 \\
$\mathrm{Total}^{-}$ & 214 & 57.7 \\
\hline
\end{tabular}

\subsection{Thermal Gravimetric Analysis (TGA)}

Surfactant heat stability is another important factor for any new surfactant designed for oilfield applications because the surfactant stays in a non-ambient environment inside the reservoir for a long period of time. Therefore, thermal decomposition studies for $\mathbf{g 1}$, g2, and g3 were conducted using 
TGA. TGA analysis is only used to assess short-term thermal stability. However, for long-term thermal analysis, surfactants were aged at reservoir conditions for a specific time. After the aging period, thermal decomposition was assessed using visual observations, FTIR, and NMR. The TGA plot of weight \% of g1, g2, and g3 versus temperature is depicted in Figure 6. The first 10-15\% weight loss of $\mathbf{g 1}$, g2, and g3 was mainly due to the loss of moisture and impurities. The second step showed a big slope at $268^{\circ} \mathrm{C}(\mathrm{g} 1), 302{ }^{\circ} \mathrm{C}(\mathrm{g} 2)$, and $260{ }^{\circ} \mathrm{C}(\mathrm{g} 3)$, exhibiting the influence of heat resulting in the structure degradation of $\mathbf{g 1}, \mathbf{g} 2$, and g3, respectively. All three surfactants showed almost identical degradation patterns; however, the GS with a secondary amine spacer (g2) exhibited comparatively higher heat stability. Overall, it was established that the synthesized gemini surfactants displayed a higher heat stability than the actual reservoir temperature $\left(\geq 90^{\circ} \mathrm{C}\right)$ and the hydrophilic nature of the spacer group showed a significant effect toward the thermal stabilities of the GSs.

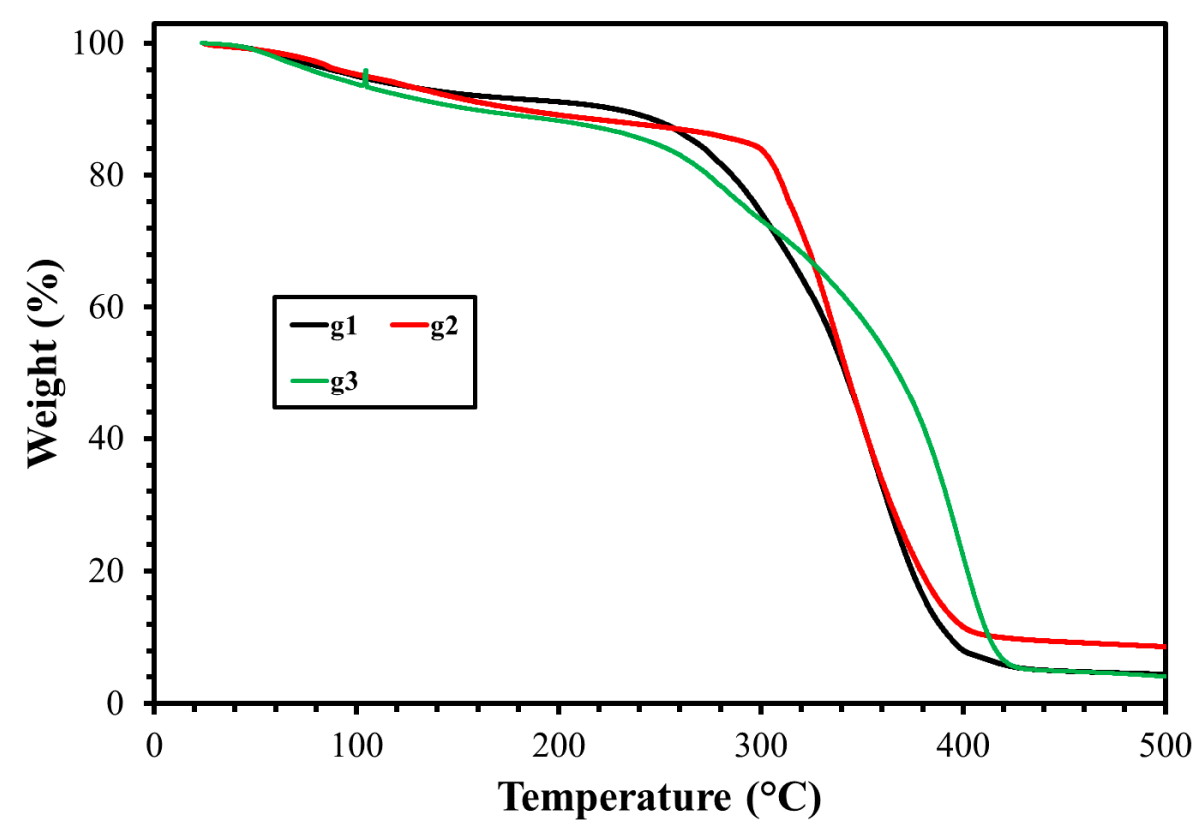

Figure 6. Thermal gravimetric analysis of $\mathbf{g 1}$, g2, and g3 with different hydrophilicity of the spacer.

\subsection{Surface Tension Measurements}

The CMC was measured with the aid of log surfactant molar concentration $(C)$ vs. surface tension $(\gamma)$ at $25{ }^{\circ} \mathrm{C}$. The occupied minimum area of surfactant $\left(\mathrm{A}_{\min }\right)$ and the maximum surface access $\left(\Gamma_{\max }\right)$ was investigated by the Gibbs equation [39].

$$
\begin{gathered}
\Gamma_{\max }=-\frac{1}{n R T}\left(\frac{d \gamma}{d \ln C}\right)_{T} \\
A_{\min }=10^{18} / N_{A} \Gamma_{\max }
\end{gathered}
$$

where $\mathrm{d} \gamma / \mathrm{d} \operatorname{lnC}$ is the gradient; $\mathrm{R}$ is the gas constant; $\mathrm{T}$ is the temperature; and $\mathrm{N}_{\mathrm{A}}$ is Avogadro's number [40].

Figures 7-9 display the surface tension values of $\mathbf{g 1}, \mathbf{g} 2$, and $\mathbf{g} 3$, respectively. The surface tension of GSs was reduced by adding surfactant until it reached the CMC. Figure 7 highlights the surface tension of $\mathbf{g} \mathbf{1}$ in $\mathrm{DW}, \mathrm{NaCl}$, and $\mathrm{SW}$, and it was observed that the $\mathrm{CMC}$ decreased with the increasing salinity of the surfactant solution $(\mathrm{DW}>\mathrm{NaCl})$ [41]. Likewise, surface tension at $\mathrm{CMC}\left(\gamma_{\mathrm{CMC}}\right)$ also decreased with increasing salinity of the surfactant solution ( $\mathrm{DW}>\mathrm{NaCl}$ ). However, no significant difference in the $\mathrm{CMC}$ and $\gamma_{\mathrm{CMC}}$ was noticed between $\mathrm{NaCl}$ and the seawater solution $(\mathrm{NaCl} \approx \mathrm{SW})$, which may be due to no significant salinity difference between $\mathrm{NaCl}$ and seawater (Table 6). This behavior was 
consistent for all three types of GSs (g1-g3) and also in agreement with the literature [37]. The CMC and $\gamma_{\mathrm{CMC}}$ depend on the molecular interaction at the interface of the water-micelle. Anything that facilitates the surfactant molecules to be adsorbed at the interface of the water-micelle will lead to a lowering in the surface tension. The presence of salts helped more closed packing at the interface by minimizing intermolecular repulsion and also promotes polar group adsorption at the air-water interface due to reduced hydration, which resulted in a lowering CMC [24,42]. In the comparison of the effect of different spacer groups on the surface properties, it was observed that the GS containing the diethyl ether spacer (g1) exhibited a lower CMC compared to those of $\mathbf{g} \mathbf{2}$ and g3, and the CMC values were found in the order of $\mathbf{g} \mathbf{2}>\mathbf{g} \mathbf{3}>\mathbf{g} \mathbf{1}$, which indicates that $\mathbf{g} \mathbf{1}$ is more prone to being adsorbed at the water-micelle interface.

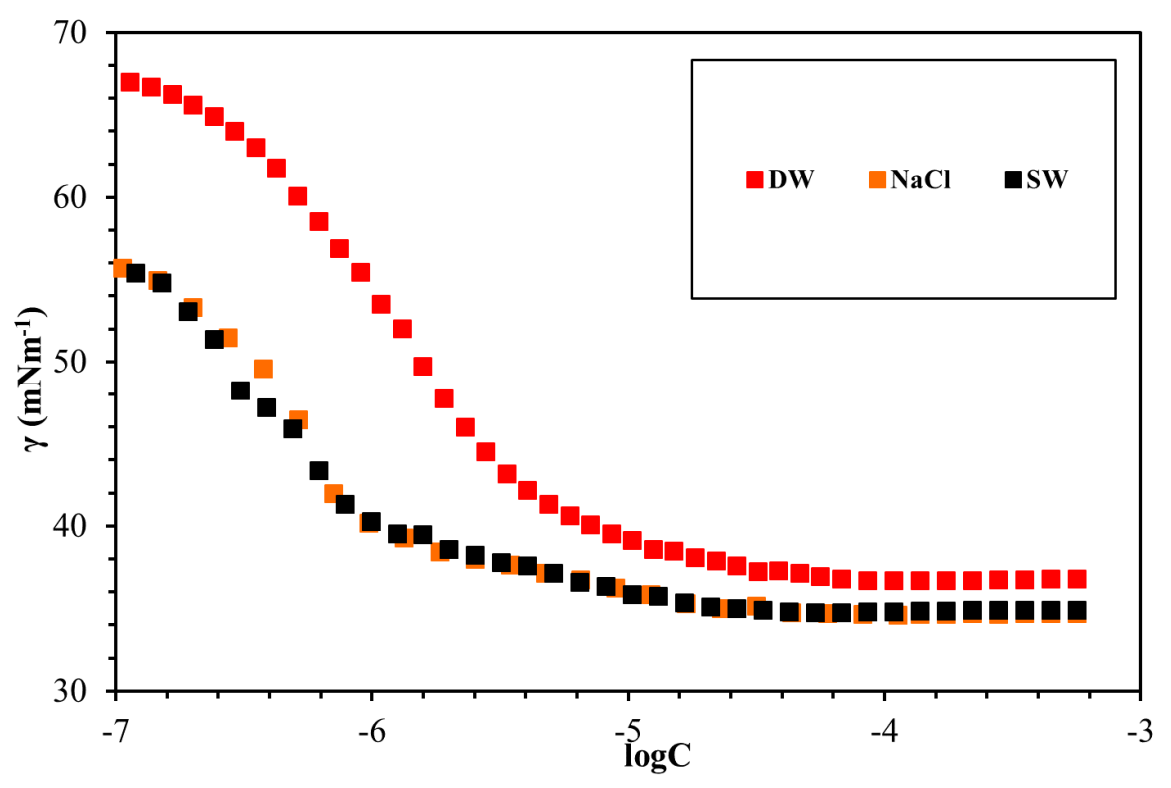

Figure 7. The surface tension of $\mathbf{g} \mathbf{1}$ at different salinities.

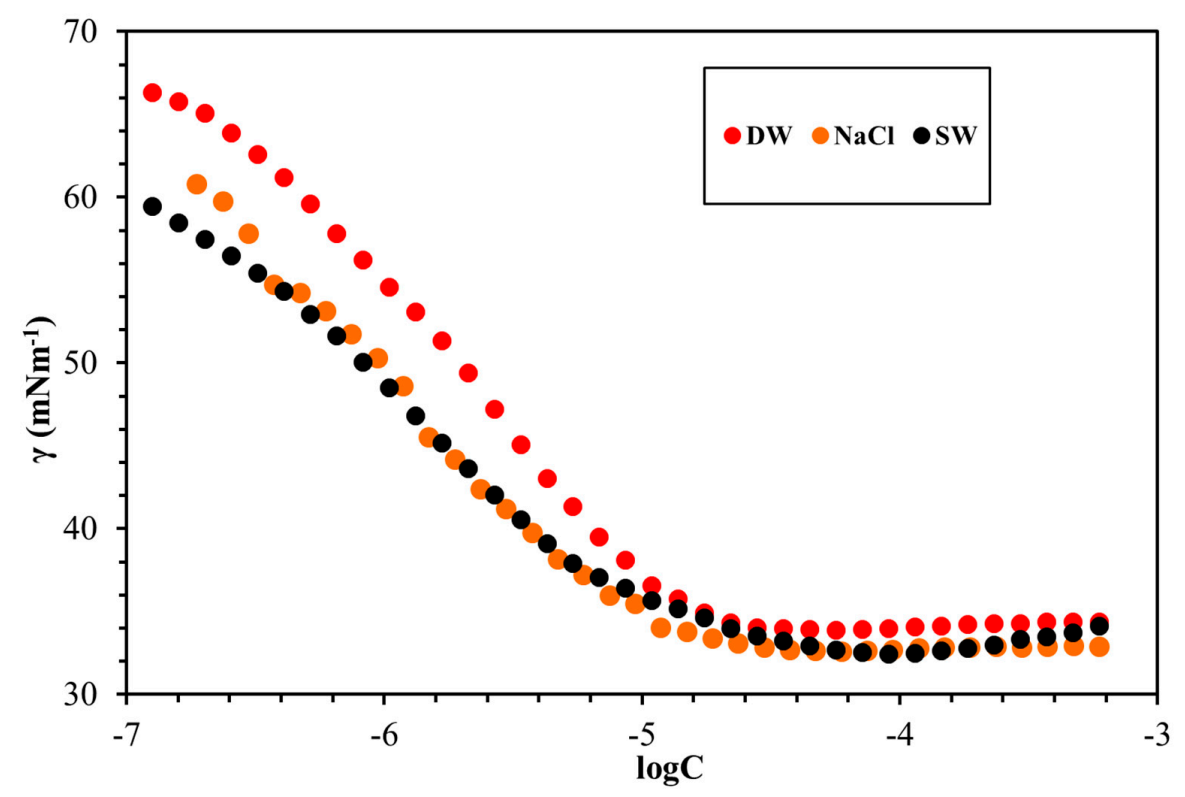

Figure 8. The surface tension of $\mathbf{g} \mathbf{2}$ at different salinities. 


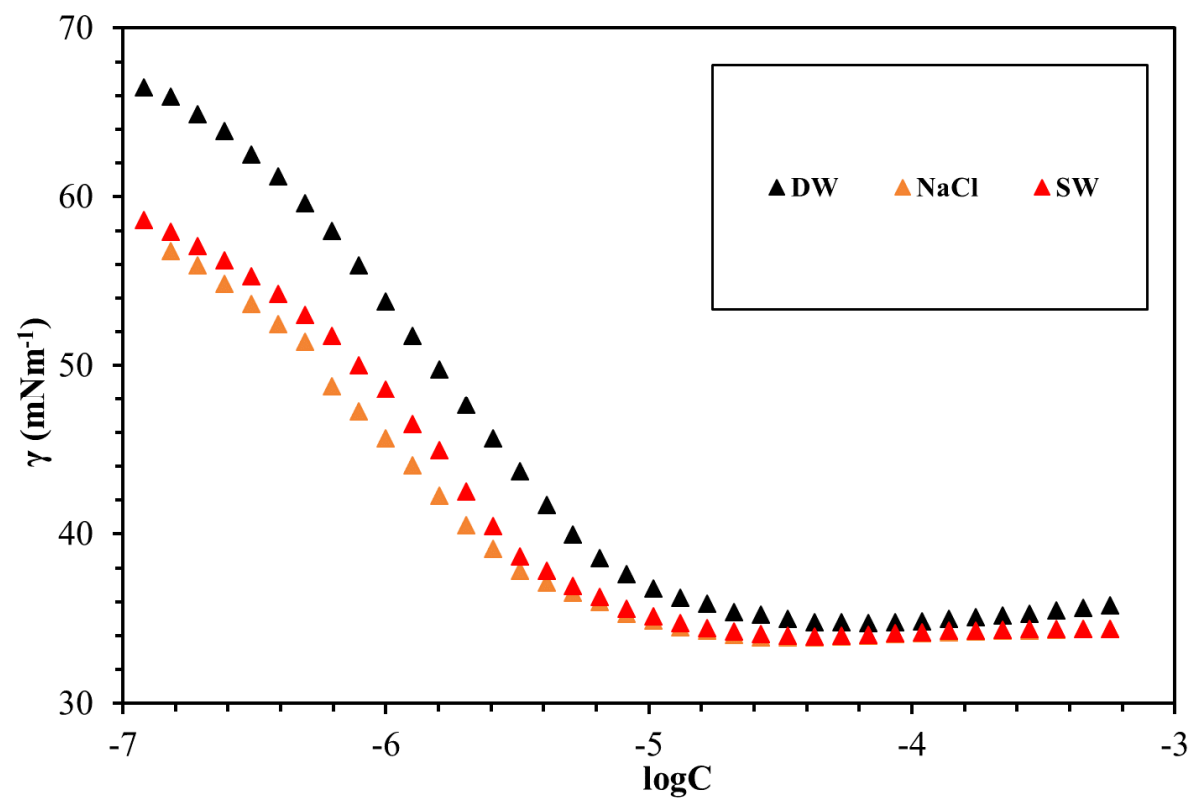

Figure 9. The surface tension of $\mathbf{g} 3$ at different salinities.

Table 6. Surface properties of $\mathbf{g 1}$, g2, and $\mathbf{g} 3$ using different salinity conditions.

\begin{tabular}{|c|c|c|c|c|c|}
\hline GSs & Solvent & $\mathrm{CMC}(\mathrm{mmol} / \mathrm{L})$ & $\gamma_{\mathrm{cmc}}(\mathrm{mN} / \mathrm{m})$ & $\Gamma_{\max } \times 10^{6}\left(\mathrm{~mol} / \mathrm{m}^{2}\right)$ & $A_{\min }\left(n^{2}\right)$ \\
\hline g1 & DW & 0.0049 & 39.64 & 3.66 & 0.45 \\
\hline g1 & $\mathrm{NaCl}$ & 0.0036 & 34.13 & 3.31 & 0.50 \\
\hline g1 & SW & 0.0029 & 34.66 & 3.17 & 0.52 \\
\hline g2 & DW & 0.0164 & 33.883 & 3.15 & 0.52 \\
\hline g2 & $\mathrm{NaCl}$ & 0.0123 & 32.914 & 2.63 & 0.63 \\
\hline g2 & SW & 0.0118 & 32.963 & 2.61 & 0.64 \\
\hline g3 & DW & 0.0102 & 34.72 & 3.28 & 0.51 \\
\hline g3 & $\mathrm{NaCl}$ & 0.0052 & 33.97 & 2.85 & 0.58 \\
\hline g3 & SW & 0.0064 & 33.65 & 3.12 & 0.52 \\
\hline
\end{tabular}

\section{Conclusions}

In this work, three GSs (g1-g3) were synthesized for oilfield application and characterized by MALDI-ToF-MS, NMR, and FTIR. The influence of the hydrophilic spacer in thermal stability and aggregation morphologies was established. The GSs presented high solubility in deionized and saltwater due to the incorporation of polyethoxylates in the backbone of the chemical structure. The aqueous stability tests displayed that the g1-g3 could maintain good competency at high salinity and high temperature conditions. The TGA showed high heat stability of all three GSs compared to the actual oilfield temperature and the GS with the secondary amine spacer (g2) exhibited comparatively higher heat stability with the retention of structural integrity up to $302^{\circ} \mathrm{C}$. It was established that the addition of salts moved the $\mathrm{CMC}$ and $\gamma_{\mathrm{cmc}}$ to smaller values in the following order $\mathrm{DW}>\mathrm{NaCl} \approx \mathrm{SW}$. A substantial decline in CMC and $\gamma_{\mathrm{cmc}}$ was measured by moving from $\mathrm{DW}$ to $\mathrm{NaCl}$. The GS containing the diethyl ether spacer (g1) was more prone to being adsorbed at the interface and formed a closely packed micelle structure that ultimately resulted in lowering the CMC. The CMC values of the GSs with different hydrophilic spacers were in the order of $\mathbf{g} 2>\mathbf{g} \mathbf{3}>\mathbf{g} 1$. The thermal and surface properties of the synthesized GSs show the practicability of using these surfactants for oilfield applications under harsh conditions.

Supplementary Materials: The following are available online at http://www.mdpi.com/1996-1944/13/5/1046/s1, Figure S1: The comparison of $1 \mathrm{H}$ NMR before and after aging. 
Author Contributions: Conceptualization, M.S.K. and S.M.S.H.; Methodology, A.M. and M.S.K.; Formal analysis, M.S.K and S.M.S.H.; Investigation, A.M. and S.M.S.H; Data curation, S.M.S.H and A.M.; Writing-original draft preparation, S.M.S.H and M.S.K.; Writing—review and editing, M.S.K and S.M.S.H.; Supervision, M.S.K.; Project administration, M.S.K. All authors have read and agreed to the published version of the manuscript.

Funding: This research was funded by the College of Petroleum Engineering \& Geoscience (CPG), King Fahd University of Petroleum \& Minerals, through a joint project with UT Austin under the grant number CPG-17-0124 and the APC was funded by College of Petroleum Engineering \& Geoscience.

Acknowledgments: The research was supported by the College of Petroleum Engineering \& Geoscience (CPG) at KFUPM through a collaborative project with The University of Texas at Austin.

Conflicts of Interest: The authors declare no conflicts of interest.

\section{References}

1. Ma, T.; Feng, H.; Wu, H.; Li, Z.; Jiang, J.; Xu, D.; Meng, Z.; Kang, W. Property Evaluation of Synthesized Anionic-Nonionic Gemini Surfactants for Chemical Enhanced Oil Recovery. Colloids Surfaces A Physicochem. Eng. Asp. 2019, 581, 123800. [CrossRef]

2. Kalam, S.; Kamal, M.S.; Patil, S.; Hussain, S.M. Role of Counterions and Nature of Spacer on Foaming Properties of Novel Polyoxyethylene Cationic Gemini Surfactants. Processes 2019, 7, 502. [CrossRef]

3. Kamal, M.S.; Hussain, S.M.S.; Fogang, L.T. Role of Ionic Headgroups on the Thermal, Rheological, and Foaming Properties of Novel Betaine-Based Polyoxyethylene Zwitterionic Surfactants for Enhanced Oil Recovery. Processes 2019, 7, 908. [CrossRef]

4. Sagir, M.; Talebian, S.H. Screening of CO2-Philic Surfactants Morphology for High Temperature-Pressure Sandstone Reservoir Conditions. J. Pet. Sci. Eng. 2020, 186. [CrossRef]

5. Sagir, M.; Tan, I.M.; Mushtaq, M.; Ismail, L.; Nadeem, M.; Azam, M.R.; Hashmet, M.R. Novel Surfactant for the Reduction of CO2/Brine Interfacial Tension. J. Dispers. Sci. Technol. 2014, 35, 463-470. [CrossRef]

6. SalahEldin Hussien, O.; Elraies, K.A.; Almansour, A.; Husin, H.; Belhaj, A.; Ern, L. Experimental Study on the Use of Surfactant as a Fracking Fluid Additive for Improving Shale Gas Productivity. J. Pet. Sci. Eng. 2019, 183. [CrossRef]

7. Ghasemi, M.; Moslemizadeh, A.; Shahbazi, K.; Mohammadzadeh, O.; Zendehboudi, S.; Jafari, S. Primary Evaluation of a Natural Surfactant for Inhibiting Clay Swelling. J. Pet. Sci. Eng. 2019, 878-891. [CrossRef]

8. Mao, J.; Wang, D.; Yang, X.; Zhang, Z.; Yang, B.; Zhang, C. Adsorption of Surfactant on Stratum Rocks: Exploration of Low Adsorption Surfactants for Reservoir Stimulation. J. Taiwan Inst. Chem. Eng. 2019, 95, 424-431. [CrossRef]

9. Khalaf, M.M.; Tantawy, A.H.; Soliman, K.A.; Abd El-Lateef, H.M. Cationic Gemini-Surfactants Based on Waste Cooking Oil as New 'Green' Inhibitors for N80-Steel Corrosion in Sulphuric Acid: A Combined Empirical and Theoretical Approaches. J. Mol. Struct. 2019. [CrossRef]

10. Gu, Y.; Yu, S.; Mou, J.; Wu, D.; Zheng, S. Research Progress on the Collaborative Drag Reduction Effect of Polymers and Surfactants. Materials 2020, 13, 444. [CrossRef]

11. Liu, L.; Pu, X.; Zhou, Y.; Zhou, J.; Luo, D.; Ren, Z. Smart Pickering Water-in-Oil Emulsion by Manipulating Interactions between Nanoparticles and Surfactant as Potential Oil-Based Drilling Fluid. Colloids Surfaces $A$ Physicochem. Eng. Asp. 2020. [CrossRef]

12. Andrunik, M.; Bajda, T. Modification of Bentonite with Cationic and Nonionic Surfactants: Structural and Textural Features. Materials 2019, 12, 3772. [CrossRef] [PubMed]

13. Mashayekhizadeh, V.; Kord, S.; Dejam, M. EOR Potential within Iran. Spec. Top. Rev. Porous Media Int. J. 2014, 5, 325-354. [CrossRef]

14. Ahmadi, M.A.; Galedarzadeh, M.; Shadizadeh, S.R. Wettability Alteration in Carbonate Rocks by Implementing New Derived Natural Surfactant: Enhanced Oil Recovery Applications. Transp. Porous Media 2015, 106, 645-667. [CrossRef]

15. Olayiwola, S.O.; Dejam, M. A Comprehensive Review on Interaction of Nanoparticles with Low Salinity Water and Surfactant for Enhanced Oil Recovery in Sandstone and Carbonate Reservoirs. Fuel 2019, 241, 1045-1057. [CrossRef]

16. Wagay, T.A.; Askari, H.; Ismail, K. Synthesis, Aggregation and Adsorption Behavior of Benzyldimethylhexadecylammonium Based Double-Chained Metallosurfactants. J. Mol. Liq. 2019. [CrossRef] 
17. Taleb, K.; Pillin, I.; Grohens, Y.; Saidi-Besbes, S. Gemini Surfactant Modified Clays: Effect of Surfactant Loading and Spacer Length. Appl. Clay Sci. 2018, 161, 48-56. [CrossRef]

18. Pal, N.; Saxena, N.; Mandal, A. Synthesis, Characterization, and Physicochemical Properties of a Series of Quaternary Gemini Surfactants with Different Spacer Lengths. Colloid Polym. Sci. 2017, 295, 2261-2277. [CrossRef]

19. Pal, N.; Saxena, N.; Mandal, A. Studies on the Physicochemical Properties of Synthesized Tailor-Made Gemini Surfactants for Application in Enhanced Oil Recovery. J. Mol. Liq. 2018, 258, 211-224. [CrossRef]

20. Hussain, S.M.S.; Kamal, M.S. Effect of Large Spacer on Surface Activity, Thermal, and Rheological Properties of Novel Amido-Amine Cationic Gemini Surfactants. J. Mol. Liq. 2017, 242, 1131-1137. [CrossRef]

21. Akram, M.; Anwar, S.; Bhat, I.A. Kabir-ud-Din. In Vitro Evaluation of the Non-Covalent Interactions of Hemoglobin with Distinctively Modified Gemini Surfactants: Effect of Structural Variation. Colloids Surfaces A Physicochem. Eng. Asp. 2017, 527, 145-157. [CrossRef]

22. Hordyjewicz-Baran, Z.; Woch, J.; Kuliszewska, E.; Zimoch, J.; Libera, M.; Dworak, A.; Trzebicka, B. Aggregation Behavior of Anionic Sulfonate Gemini Surfactants with Dodecylphenyl Tails. Colloids Surfaces A Physicochem. Eng. Asp. 2015, 484, 336-344. [CrossRef]

23. Menger, F.M.; Keiper, J.S.; Azov, V. Gemini Surfactants with Acetylenic Spacers. Langmuir 2000, 16, $2062-2067$. [CrossRef]

24. Wang, X.; Wang, J.; Wang, Y.; Yan, H.; Li, P.; Thomas, R.K. Effect of the Nature of the Spacer on the Aggregation Properties of Gemini Surfactants in an Aqueous Solution. Langmuir 2004, 20, 53-56. [CrossRef]

25. Zhang, T.; Cao, X.; Wang, X.; Song, C. Synthesis, Surface Activity and Thermodynamic Properties of Cationic Gemini Surfactants with Diester and Rigid Spacers. J. Mol. Liq. 2017, 230, 505-510. [CrossRef]

26. Zhou, L.; He, Y.; Gou, S.; Zhang, Q.; Liu, L.; Tang, L.; Zhou, X.; Duan, M. Efficient Inhibition of Montmorillonite Swelling through Controlling Flexibly Structure of Piperazine-Based Polyether Gemini Quaternary Ammonium Salts. Chem. Eng. J. 2019, 123190. [CrossRef]

27. Mao, J.; Yang, X.; Wang, D.; Li, Y.; Zhao, J. A Novel Gemini Viscoelastic Surfactant (VES) for Fracturing Fluids with Good Temperature Stability. RSC Adv. 2016. [CrossRef]

28. Yang, X.; Mao, J.; Zhang, H.; Zhang, Z.; Zhao, J. Reutilization of Thickener from Fracturing Flowback Fluid Based on Gemini Cationic Surfactant. Fuel 2019, 235, 670-676. [CrossRef]

29. Migahed, M.A.; elgendy, A.; EL-Rabiei, M.M.; Nady, H.; Zaki, E.G. Novel Gemini Cationic Surfactants as Anti-Corrosion for X-65 Steel Dissolution in Oilfield Produced Water under Sweet Conditions: Combined Experimental and Computational Investigations. J. Mol. Struct. 2018, 1159, 10-22. [CrossRef]

30. Cao, X.-L.; Feng, J.; Guo, L.-L.; Zhu, Y.; Zhang, L.; Zhang, L.; Luo, L.; Zhao, S. Dynamic Surface Dilational Properties of Anionic Gemini Surfactants with Polyoxyethylene Spacers. Colloids Surfaces A Physicochem. Eng. Asp. 2016, 490, 41-48. [CrossRef]

31. Chen, Z.; Han, X.; Kurnia, I.; Yu, J.; Zhang, G.; Li, L. Adoption of Phase Behavior Tests and Negative Salinity Gradient Concept to Optimize Daqing Oilfield Alkaline-Surfactant-Polymer Flooding. Fuel 2018, 232, 71-80. [CrossRef]

32. Parikh, K.; Singh, S.; Desai, A.; Kumar, S. An Interplay between Spacer Nature and Alkyl Chain Length on Aqueous Micellar Properties of Cationic Gemini Surfactants: A Multi-Technique Approach. J. Mol. Liq. 2019, 278, 290-298. [CrossRef]

33. Ahel, M.; Giger, W. Aqueous Solubility of Alkylphenols and Alkylphenol Polyethoxylates. Chemosphere 1993, 26, 1461-1470. [CrossRef]

34. Chu, Z.; Feng, Y. A Facile Route towards the Preparation of Ultra-Long-Chain Amidosulfobetaine Surfactants. Synlett 2009, 16, 2655-2658.

35. Devinsky, F.; Masarova, L.; Lacko, I.; Bittererova, F.; Tomeckova, L.; Rozycka-Roszak, B.; Wittek, S.; Przestalski, S. Alkanediyl-CK,v-Bis(Dimethylalkylammonium Bromide) Surfactants. 1. Effect of the Spacer Chain Length on the Critical Micelle Concentration and Micelle Ionization Degree. Langmuir 1991, 7, 1072-1075.

36. Kaczerewska, O.; Brycki, B.; Ribosa, I.; Comelles, F.; Garcia, M.T. Cationic Gemini Surfactants Containing an O-Substituted Spacer and Hydroxyethyl Moiety in the Polar Heads: Self-Assembly, Biodegradability and Aquatic Toxicity. J. Ind. Eng. Chem. 2018, 59, 141-148. [CrossRef] 
37. Zhang, W.; Mao, J.; Yang, X.; Zhang, H.; Zhang, Z.; Yang, B.; Zhang, Y.; Zhao, J. Study of a Novel Gemini Viscoelastic Surfactant with High Performance in Clean Fracturing Fluid Application. Polymers 2018, 10, 1215. [CrossRef]

38. Ghumare, A.K.; Pawar, B.V.; Bhagwat, S.S. Synthesis and Antibacterial Activity of Novel Amido-Amine-Based Cationic Gemini Surfactants. J. Surfactants Deterg. 2013, 16, 85-93. [CrossRef]

39. Hussain, S.M.S.; Kamal, M.S.; Fogang, L.T. Effect of Internal Olefin on the Properties of Betaine-Type Zwitterionic Surfactants for Enhanced Oil Recovery. J. Mol. Liq. 2018, 266, 43-50. [CrossRef]

40. Nessim, M.I.; Osman, M.M.; Ismail, D.A. Surface-Active Properties of New Cationic Gemini Surfactants with Cyclic Spaceractive Properties of New Cationic Gemini Surfactants with Cyclic Spacer Surface-Active Properties of New Cationic Gemini Surfactants with Cyclic Spacer. J. Dispers. Sci. Technol. 2018, 39, 1047-1055. [CrossRef]

41. Zhao, T.; Dong, Z.; Peng, G.; Xing, J.; He, Y. Synthesis and Properties of Quaternary Ammonium Gemini Surfactants with Hydroxyl Groups. Russ. J. Appl. Chem. 2016, 89, 650-662. [CrossRef]

42. Garcia, M.T.; Kaczerewska, O.; Ribosa, I.; Brycki, B.; Materna, P.; Drgas, M. Hydrophilicity and Flexibility of the Spacer as Critical Parameters on the Aggregation Behavior of Long Alkyl Chain Cationic Gemini Surfactants in Aqueous Solution. J. Mol. Liq. 2017, 230, 453-460. [CrossRef]

(C) 2020 by the authors. Licensee MDPI, Basel, Switzerland. This article is an open access article distributed under the terms and conditions of the Creative Commons Attribution (CC BY) license (http://creativecommons.org/licenses/by/4.0/). 